\section{HOW WHITE ARE YOUR TEETH?}

A smartphone app has been created which allows people to monitor the colour of their teeth and see the effect of all kinds of tooth whitening products upon them.

The Teeth Whitening App, free from the Apple Store and coming soon on Android devices, takes a photograph of your teeth and then gives a 'white percentage'. This photograph can then be archived and compared to further photographs taken after the use of tooth whitening products.

The app's creator, Roman Zilberstein, made the app to encourage people to look after and clean their teeth by providing an easy visual inspection and the ability to keep a record of improvements.

The BDJ's News Editor was encouraged to discover that, according to the app, her teeth are $75 \%$ white.

The Teeth Whitening App is available at: https://itunes.apple. com/us/app/teeth-whitening-app/ id651412755? $1 \mathrm{~s}=1 \mathrm{ftmt}=8$.

\section{THE SECRETS TO MARKETING SUCCESS}

On 9 November 2013, Chris Baker of Corona Design \&t Communication will take to the podium at the BACD Annual Conference with his lecture: 'The Media - Your Friend'. In his talk, Chris will explore the plethora of different media options available to the savvy dental marketer, and will share his strategies for dental marketing success.

Chris will explain that the term 'media' now includes online media resources such as blogging platforms, websites and social media. This can be daunting, so Chris aims to explain everything and provide hints and tips. www.bacd.com

\section{EXCELLENT PATIENT COMPLIANCE}

Patient compliance with UltraDEX Oral Healthcare Kits from Periproducts is excellent and the demand for the kits is constantly increasing with hygienists and dentists using them for complete periodontal and oral hygiene treatments, fresh breath clinics, whitening maintenance or as part of their periodontal assessment, incorporating them into their treatment plans.

Developed and recommended by dental professionals and backed by extensive research, the UltraDEX range delivers fresh breath confidence, whitening maintenance and exceptional oral health. The technology is antibacterial, working with the natural oral $\mathrm{pH}$ level, releasing the appropriate amount of active ingredient to meet the individual needs of each mouth. UltraDEX eliminates, not simply masks, odour-causing volatile sulphur compounds on contact. Suitable for sensitive teeth it gently lifts organic stains and breaks down bacterial plaque biofilm. Bacteria cannot become resistant and regrowth is inhibited.

For samples, to order, or for advanced free CPD webinar training, email your details to dental@periproducts.co.uk.

\section{ELIMINATING MALODOUR}

CB12 is a revolutionary product designed specifically to tackle halitosis at its source. Using a combination of zinc acetate and chlorhexidine diacetate, the bespoke mouth rinse eliminates malodour and has been proven to relieve the sufferer from symptoms for at least 12 hours.

Ninety percent of all cases of halitosis have been found to originate within the oral cavity. As oral bacteria break down food particles, usually in the crypts at the back of tongue or in periodontal pockets, volatile sulphur compounds, or VSCs, are released. CB12 has been proven to effectively neutralise these odour-causing gases, giving sufferers back their confidence and self-esteem.

Available in mint menthol and mild mint menthol, CB12 is suitable for all patients over the age of 12 years, and can used either once or twice a day for hours of protection against halitosis. It even contains fluoride to help prevent tooth decay and to encourage a high standard of general oral health.

For more information on CB12, visit www.cb12.co.uk.
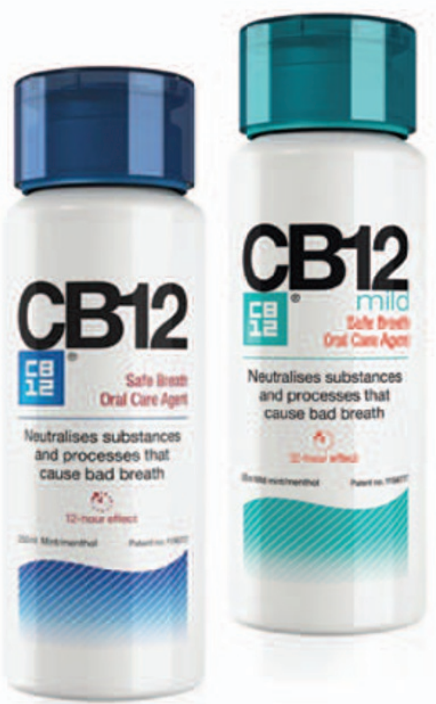

\title{
FILL YOUR EMPTY APPOINTMENTS WITH EASE
}

Zesty is a new online booking service that focuses on generating new patient appointments for your practice.

It is estimated that more than one million people search online for dental assistance every month in London alone. Zesty is there to point as many of them as possible towards your practice. Zesty is simple to set up and allows you to find patients to fill same day, next day and future appointments.

Using Zesty can also help to improve the service you provide your patients, allowing them to book their appointments online, quickly and with no fuss. It also sends them a SMS reminder when their appointment is coming up so that you won't have to suffer the financial losses of missed appointments.

With the opportunity to make money from your vacant or cancelled appointments today, what are you waiting for? Register your practice and upload all of your free appointment times. Simply email hello@zesty.co.uk, visit www.zesty.co.uk or call 07775967713 for more details. 